\title{
Blended Learning: Features of Application in the Modern Educational System
}

\author{
Bevzo Galina \\ Ph.D., Associate Professor \\ Concordia Ukrainian-American University (Ukraine) \\ Vanda Vyshkivska \\ Ph.D., Associate Professor \\ Dragomanov National Pedagogical University (Ukraine) \\ Iryna Titarenko \\ PhD, Pedagogical Sciences, Senior Lecturer, \\ Head of the bachelor program at Public Relations Department, \\ National University of Kyiv-Mohyla Academy (Ukraine) \\ Anzhelika Remnova \\ PhD, Pedagogical Sciences, Senior Lecturer \\ Dragomanov National Pedagogical University (Ukraine)
}

\begin{abstract}
The article analyzes the potential and possibilities of the method of blended learning as a didactic means of implementing the transition from the traditional model of learning to the integrated one with involving electronic environments and resources. The existing models of blended learning are considered, the ways of their adaptation to the conditions of studying at institutions of higher education are discussed. It will help to improve the quality of education as well as to provide opportunities for the implementing various educational models, forms and means of education. It is pointed out the problems which hinder the effective and rapid integration of e-learning environments. Some strategic initiatives to solve them are proposed.

It is proved that blended learning technology involves the transformation of the student's position from the object to the active subject of teaching, and the teacher - from the main source of knowledge to the organizer of the students` learning process. Blended learning is justified as an educational model which bases on the integration of traditional face-to-face and electronic education systems and provides personalization of the learning process by means of providing the learners with the opportunity to choose conditions and control over the process of mastering the set of necessary competencies.

Key words: blended learning, distance learning, information technologies, e-learning, informatization of education.

Актуальність дослідження і постановка проблеми. У сучасних умовах зросли і змінилися соціальні вимоги та запити суспільства до системи освіти. Підвищеною є увага до питань методології та методики викладання, до особистісної
\end{abstract}


орієнтації освітнього процесу, індивідуалізації освітніх програм і способів їх реалізації. Особлива увага приділяється можливостям, які надають інформаційні технології. Відповідно з'являється необхідність інтеграції традиційних методів навчання (очного навчання) і нових електронних методів. Однією з ефективних форм навчання стає сьогодні змішане навчання.

Теоретико-практичні аспекти змішаного навчання досліджували вітчизняні (А. Бурмістрова, Н. Болюбаш, В. Гнезділов, В. Голубєва, Є. Желнова, М.Коваль, В. Кухаренко, В.Маняхіна; Е. Б. Новікова, А. Стрюк, Н. Ф. Телешева Ю. Триус, Л. Шапран С. В. Шокалюк та ін.) та зарубіжні (С. Грехем, С. Моебс, С. Вейбелзах, Д. Пейнтер, Р. Сченк) науковці.

Ю. Триус, В. Кухаренко трактують «змішане навчання» як цілеспрямований процес здобування знань, набуття вмінь та навичок в умовах інтеграції аудиторної та позааудиторної навчальної діяльності суб'єктів освітнього процесу на основі впровадження i взаємного доповнення технологій традиційного, електронного, дистанційного та мобільного навчання за наявності самоконтролю студента за часом, місцем, маршрутами та темпом навчання [5].

О. Кривонос «змішане навчання» розуміє як освітню концепцію, в рамках якої учень отримує знання самостійно (онлайн) і очно (з викладачем), що дає можливість контролювати час, місце, темп і спосіб (траєкторію) вивчення матеріалу [3]. А також як інструмент модернізації сучасної освіти, заснований на інтеграції традиційних технологій організації освітнього процесу та технології електронного навчання» [4].

М.Кадемія - як навчання, в межах якого студент одержує знання очно i самостійно он-лайн, i яке передбачає створення комфортного освітнього інформаційного середовища, системи комунікацій [2].

Як цілеспрямований процес передачі й засвоєння знань, умінь, навичок і способів пізнавальної діяльності людини, заснований на поєднанні технологій традиційного, комп'ютерно-орієнтованого, дистанційного та мобільно-орієнтованого навчання обгрунтовує сутність змішаного навчання Г.Ткачук [9].

Мета статті - обгрунтувати особливості застосування змішаного навчання в сучасній освітній системі. 
Виклад основного матеріалу. Сучасний етап розвитку освітньої діяльності визначається домінуванням інформаційно-комунікаційних технологій, які дозволяють інтенсифікувати форми і методи традиційних підходів до навчання. Все більша кількість людей прагне отримати освіту з мінімальними втратами часу, оскільки темп життя залишає його все менше для традиційного очного навчання. Освіта нового покоління орієнтує на перехід від суб'єкт-об'єктного навчання до суб'єкт-суб'єктного, у якому педагог виступає в ролі організатора освітнього процесу [1]. Поступово змінюються принципи організації освітнього процесу, створюються умови для реалізації динамічного персоналізованого навчання із застосуванням електронного навчання, дистанційних освітніх технологій [14].

М. Моїсеєва говорить про електронне навчання в контексті використання Інтернет- технологій в навчальному процесі, де реалізуються педагогічні технології [6].

Badrul Khan визначив elearning як «...використання нових інформаційних технологій, технологій мультимедіа і Інтернет в процесі навчання [11].

Полат Є. С.: “дистанційне навчання - це систематична організація навчання, побудована на взаємодії викладача та студента, студентів між собою на віддаленні, що відображає всі властиві навчальному процесу елементи (організаційні форми, цілі, засоби навчання, зміст) своєрідними прийомами ІКТ та Internet-технологіями" [8].

Вчений Хуторський А. В. дистанційне навчання тлумачить як “навчання, в якому суб’єкти перебувають на відстані, реалізовуючи освітній процес за сприяння засобів телекомунікацій” [10].

Однією з сучасних освітніх технологій є змішане навчання, або blended learning, в основі якого лежить концепція об'єднання технологій «класно-урочної системи», електронного навчання, дистанційних освітніх технологій. Серед основних переваг даного навчання можна назвати наступні: - можливість освоїти потрібні знання і вміння в зручному форматі; - планування і розуміння того, яку потребу навчання має задовільнити і які результати принести; - забезпечення ефективних інструментів управління навчанням; - зниження тимчасових і фінансових витрат на навчання, не втрачаючи при цьому переваг традиційного підходу; - забезпечення активної соціальної взаємодії учнів ( студентів) між собою і з викладачами; - можливість здійснювати навчання у будь-який момент, незалежно від часу і місця; - різноманітність 
використовуваних дидактичних підходів; - поліпшення якості навчання (в тому числі за рахунок використання більш ефективних засобів навчання); - індивідуальний контроль за навчанням; природне освоєння учнями сучасних засобів організації навчання, комунікацій; - пріоритет самостійної діяльності учня; організація індивідуальної підтримки навчальної діяльності кожного учня; - гнучкість освітньої траєкторії; інтеграція онлайнового і офлайнового навчально-методичного контента багаторазового використання.

У науковій літературі найбільш вживаними є такі визначення досліджуваного терміну. Змішане навчання - це такі навчальні програми, в рамках яких студенти частково навчаються в електронному, онлайновому форматі із забезпеченням контролю над термінами, ходом і темпом навчання; частково ж навчання відбувається очно. В такому навчанні використовуються різні модальності, щоб забезпечити в результаті інтегрований навчальний досвід [13].

MacMillan Dictionary трактує «змішане навчання» як такий метод навчання, який комбінує різні ресурси, зокрема, елементи очних навчальних сесій та електронного навчання [12].

Слід зауважити, що поєднання онлайнових і офлайнових технологій дозволяє зробити навчання ефективним, економічним i зручним, а освітній процес інтерактивним, особистісно-орієнтованим i адаптивним для всіх зацікавлених $у$ навчанні сторін.

Безумовно, існує ряд причин, які можуть обумовити неефективне використання технологій дистанційного та електронного навчання: - відсутність ефективних засобів управління освітою; - відсутність коштів на розробку навчального контенту; - брак педагогічних кадрів у сфері технологій дистанційного навчання; - відсутність сучасних засобів навчання; - неналежне технічне і програмне забезпечення; - відставання навчальних програм ( за змістовим наповненням) від реального життя тощо.

Необхідно зауважити і про те, що освіта за допомогою Інтернет - технологій явище порівняно нове. На сьогодні $\epsilon$ ще недостатньо сформованою культура спілкування і здійснення професійної діяльності через Інтернет. Окрім того: - більшість навчальних матеріалів, створених для традиційного навчання, не підходять для використання в онлайн або змішаному режимі; - студент, навчаючись віддалено і тільки 
за допомогою засобів інформаційних технологій, не отримує можливості напрацювати ті необхідні навички, які він міг би напрацьовувати на лекціях і семінарах; - бракує професіоналізму при розробці навчальних онлайн - матеріалів і існує необхідність спеціальної підготовки викладачів для роботи з новими технологіями; - розроблені курси не відповідають різним стандартам інтерфейсу, графіки і т.ін., можуть викладатися тільки одним навчальним закладом або тільки одним викладачем; недостатнім є рівень сформованості навичок роботи з інформаційними системами у всіх учасників освітнього процесу.

На тлі означених проблем змішана модель навчання дозволяє вирішити такі завдання: - для учнів - розширення освітніх можливостей суб'єктів навчання за рахунок збільшення доступності та гнучкості освіти, врахування індивідуальних освітніх потреб, а також темпу засвоєння навчального матеріалу; реалізація індивідуальних навчальних планів $з$ необмеженим вибором предметів, рівня їх засвоєння і способів організації навчальної діяльності; персоналізація освітнього процесу; максимальна об'єктивізація процедури і результатів оцінювання. Для викладачів: - підвищення ефективності педагогічної діяльності з метою досягнення нових освітніх результатів; використання нових видів контролю та комунікації в педагогічному процесі; можливість якісно організувати співпрацю 3 високомотивованими учнями; трансформування стилю педагога: від трансляції знань до інтерактивної взаємодії з учнями, що, своєю чергою, сприяє конструюванню останніми власних знань. Для організації освітнього процесу: можливість економії коштів за рахунок підвищення рівня ефективності педагогічної діяльності; залучення додаткового контингенту учнів завдяки організації багатопрофільного навчання; вирішення проблеми дефіциту педагогічних кадрів; інтенсифікація навчальної діяльності 3 метою економії часу для реалізації інших освітніх і культурних потреб.

Відповідно змішане навчання можна розглядати як педагогічну ідею, яка інтегрує ефективність і перспективи соціалізації колективної роботи в аудиторії 3 провідними технологічними можливостями навчання у режимі онлайн середовища. При цьому навчальна діяльність здійснюється і під безпосереднім керівництвом педагога, i самостійно (з електронними ресурсами, індивідуально або в групах).

Найбільш типовими моделями змішаного навчання Нагаєва I.O. визначає такі: 
1. Модель «Face-to-Face Driver»: значна частина навчальної програми вивчається в школі за безпосередньої взаємодії з учнями; електронне навчання використовується в якості доповнення до основної програми.

2. Ротаційна модель: чергування способів роботи з навчальними матеріалами при засвоєнні освітньої програми; навчальний час розподілено між індивідуальним електронним навчанням і навчанням в аудиторії.

3. Flex модель (гнучка модель): переважне використання електронного навчання; забезпечення онлайн, офлайн і очної підтримки учнів; наявність індивідуального розкладу; робота в малих групах; організація групових проектів; індивідуальне навчання.

4. Self-blend модель (Модель «навчального меню»): вивчення одного або декількох електронних навчальних курсів повністю онлайн; віз можна одночасне навчання в різних установах [7].

Кожна модель відрізняється переважанням однієї з трьох складових технології змішаного навчання: 1. Пряма особиста взаємодія учасників освітнього процесу. 2. Інтерактивна взаємодія, опосередкована комп'ютерними телекомунікаційними технологіями і електронними інформаційно-освітніми ресурсами. 3. Самоосвіта. Студенти стають слухачами, викладачі - тьюторами, - організаторами освітнього процесу. Діяльність викладача полягає в координації діяльності учнів як очно, так і дистанційно в умовах високотехнологічного інформаційно-освітнього середовища, вибудовуванні індивідуальних освітніх траєкторій; організації різних видів діяльності 3 використанням інформаційно-освітніх ресурсів; відбору електронного освітнього контенту.

В умовах змішаного навчання викладач забезпечує зворотний зв'язок за допомогою коментування прогресу і швидкості проходження навчального матеріалу, успішності його виконання завдяки функціоналу інформаційного освітнього середовища: відеоконференції, форуми, чати та ін. Крім того, викладач безперервно здійснює моніторинг навчального процесу та комплексний аналіз проміжних результатів діяльності кожного учня (студента) за допомогою перевірки відомостей про активність роботи в мережі, визначення якості виконаних у тестовій формі контрольних 
завдань та кількості спроб виконання того чи іншого завдання, звернення до додаткових освітніх ресурсів.

Висновок. Отже, 3 метою підвищення ефективності змішаного навчання, необхідно, аби його програма мала продуману архітектуру (визначені цілі навчання, цільова аудиторія, потреби суб'єктів навчання, розклад, технології, методи, засоби підтримки навчання; вимоги до бюджету i кадрового забезпечення, очікувані результати) з послідовними переходами між різними видами і типами навчальної активності. Відтак, для змішаного навчання характерним $\epsilon$ збереження загальних традиційних принципів побудови освітнього процесу з включенням елементів Інтернетнавчання. Співвідношення цих двох форм навчання (розвиток змішаної форми навчання), на наш погляд, може стати одним із ключових напрямів модернізації всієї освітньої сфери.

\section{References}

1. Vyshkivska V.B. Subiektnist studentiv u navchalnomu protsesi-neobkhidna umova formuvannia profesiinoi kompetentnosti. [Subjectivity of students in the educational process is a necessary condition for the formation of professional competence.] Naukovyi chasopys NPU imeni M.P.Drahomanova. 2008. Vyp.8 (18). C. 2-4.

2. Kademiia M.Iu. Vykorystannia zmishanoi tekhnolohii navchannia $u$ dystantsiinii osviti. Suchasni informatsiini tekhnolohii ta innovatsiini metodyky navchannia $v$ pidhotovtsi fakhivtsiv: metodolohiia, teoriia, dosvid, problemy. [Use of blended learning technology in distance education. Modern information technologies and innovative teaching methods in training: methodology, theory, experience, problems.] KyivVinnytsia, 2016. Vyp. 44. S.330-333.

3. Kryvonos O. M. Vykorystannia informatsiino-komunikatsiinykh tekhnolohii v navchanni: navch. posibnyk [The use of information and communication technologies in education: textbook. Manual] / O. M. Kryvonos. Zhytomyr: Vyd-vo ZhDU im. I. Franka, 2013. $182 \mathrm{~s}$

4. Kryvonos O. M., Korotun O. V. Zmishane navchannia yak osnova formuvannia IKT-kompetentnosti vchytelia. Naukovi zapysky Kirovohradskoho derzhavnoho pedahohichnoho universytetu imeni V.Vynnychenka. Seriia: Problemy metodyky fizykomatematychnoi i tekhnolohichnoi osvity. [Blended learning as a basis for the formation of ICT competence of teachers. Scientific notes of Kirovohrad State Pedagogical University named after V. Vynnychenko. Series: Problems of methods of physical-mathematical and technological education.] Kirovohrad, 2015. Vyp. 8 (II). S.19-23.

5. Kukharenko V. M., Berezenska S. M., Buhaichuk K. L. Teoriia ta praktyka zmishanoho navchannia: monohrafiia. [Theory and practice of blended learning: a monograph.] Kharkiv : Miskdruk, NTU KhPI, 2016. 284 s. 
6. Moyseeva M.V. Ynternet-obuchenye: tekhnolohyy pedahohycheskoho dyzaina; pod red. kand. ped. nauk M. V. Moyseevoi. [E-learning: pedagogical design technologies; under ed. Cand. ped. Sciences MV Moiseeva.] M.: Yzd. dom «Kameron», 2004. 216 s.

7. Nahaeva Y.A. Modelyrovanye protsessa prepodavanyia v vyrtualnom obrazovatelnom pro-stranstve vuza [Modeling of the teaching process in the virtual educational space of the university] // Setevoi nauchno-praktycheskyi zhurnal [Network scientific-practical journal] «Perspektyvы nauky y obrazovanyia». № 4. 2013. S. 79 - 92.

8. Polat E. S., Bukharkyna M. Yu., Moyseeva V. M., Petrov A. E. Sovremennble pedahohycheskye y ynformatsyonnble tekhnolohyy $v$ systemeobrazovanyia: ucheb. posob. dlia stud. ped. vuzov y systembipovblsh. kvalyf. ped. Kadrov [Modern pedagogical and information technologies in the system of education: textbook. allowance. for students. ped. universities and systems. qual. ped.] / editor E. S. Polat. 4-e yzd., ster. M.: Yzdatelskyi tsentr "Akademyia", 2009. 272 s.

9. Tkachuk H.V. Teoretychni $i$ metodychni zasady praktychno-tekhnichnoi pidhotovky maibutnikh uchyteliv informatyky $v$ umovakh zmishanoho navchannia: avtoref. dys. ...dokt. ped. nauk: [Theoretical and methodical bases of practical and technical preparation of future teachers of computer science in the conditions of mixed training: author's ref. Ph.D. dis.] 13.00.02. Kyiv, 2019. 42 c.

10. Khutorskoi A. V. Praktykum po dydaktyke y sovremennblm metodykam obuchenyia. [Workshop on didactics and modern teaching methods.] SPb.: Pyter, 2004. $541 \mathrm{~s}$.

11. Badrul Khan A framework for e-Learning / Khan Badru [elektronnyi resurs]. Address: http://www.bookstoread.com/framework

12. Means, B., Toyama, Y., Murphy, R., Bakia, M., \& Jones, K. (2010, September). Evaluation of EvidenceBased Practices in Online Learning: A Meta-Analysis and Review of Online Learning Studies

13. Staker, H., \& Horn, M. B. (2012). Classifying K-12 Blended Learning. Mountain View, CA: Innosight Institute. http://www.christenseninstitute.org/wpcontent/uploads/2013/04/Classifying-K-12-blended-learning.pdf

14. Vyshkivska V., Shykyrynska O. Orhanizatsiia protsesu navchannia $v$ novii ukrainskii shkoli: teoretyko-praktychnyi aspekt. [Organization of the learning process in the new Ukrainian school: theoretical and practical aspect.] Molod i rynok. 11 (178). 2019. C. 115-119.

\section{Translation of the References to the Author's Language}

\section{Jimepamypa}

1. Вишківська В.Б. Суб'єктність студентів у навчальному процесі-необхідна умова формування професійної компетентності. Науковий часопис НПУ імені М.П.Драгоманова. 2008. Вип.8 (18). С. 2-4.

2. Кадемія М.Ю. Використання змішаної технології навчання у дистанційній освіті. Сучасні інформаційні технології та інноваційні методики навчання в підготовці 
фахівців: методологія, теорія, досвід, проблеми. Київ-Вінниця, 2016. Вип. 44. C.330-333.

3. Кривонос О. М. Використання інформаційно-комунікаційних технологій в навчанні: навч. посібник / О. М. Кривонос. Житомир: Вид-во ЖДУ ім. І. Франка, 2013. 182 с

4. Кривонос О. М., Коротун О. В. Змішане навчання як основа формування IКТкомпетентності вчителя. Наукові записки Кіровоградського державного педагогічного університету імені В.Винниченка. Серія: Проблеми методики фізико-математичної і технологічної освіти. Кіровоград, 2015. Вип. 8 (II). С.1923.

5. Кухаренко В. М., Березенська С. М., Бугайчук К. Л. Теорія та практика змішаного навчання: монографія. Харків : Міськдрук, НТУ ХПІ, 2016. 284 с.

6. Моисеева М.В. Интернет-обучение: технологии педагогического дизайна; под ред. канд. пед. наук М. В. Моисеевой. М.: Изд. дом «Камерон», 2004. 216 с.

7. Нагаева И.А. Моделирование процесса преподавания в виртуальном образовательном про-странстве вуза // Сетевой научно-практический журнал «Перспективы науки и образования». № 4, 2013. С. 79 - 92.

8. Полат Е. С., Бухаркина М. Ю., Моисеева В. М., Петров А. Е. Современные педагогические и информационные технологии в системеобразования: учеб. пособ. для студ. пед. вузов и системыповыш. квалиф. пед. Кадров / под ред. Е. С. Полат. 4-е изд., стер. М.: Издательский центр “Академия”, 2009. 272 с.

9. Ткачук Г.В. Теоретичні і методичні засади практично-технічної підготовки майбутніх учителів інформатики в умовах змішаного навчання: автореф. дис. ...докт. пед. наук: 13.00.02. Київ, 2019. 42 с.

10. Хуторской А. В. Практикум по дидактике и современным методикам обучения. СПб.: Питер, 2004. 541 с.

11. Badrul Khan A framework for e-Learning / Khan Badru [електронний ресурс]. Режим доступу : http://www.bookstoread.com/framework

12. Means, B., Toyama, Y., Murphy, R., Bakia, M., \& Jones, K. (2010, September). Evaluation of EvidenceBased Practices in Online Learning: A Meta-Analysis and Review of Online Learning Studies

13. Staker, H., \& Horn, M. B. (2012). Classifying K-12 Blended Learning. Mountain View, CA: Innosight Institute. http://www.christenseninstitute.org/wp-content/uploads/2013/04/Classifying-K-12blended-learning.pdf

14. Vyshkivska V., Shykyrynska O. Orhanizatsiia protsesu navchannia v novii ukrainskii shkoli: teoretyko-praktychnyi aspekt. Molod i rynok. 11 (178). 2019. C. 115-119. 